\title{
Jaeger Eye Chart
}

National Cancer Institute

\section{Source}

National Cancer Institute. Jaeger Eye Chart. NCI Thesaurus. Code C130175.

A diagrammatic method to test visual acuity that uses paragraphs of text in differing font sizes to assess near vision. 